\title{
A theory of macromotives
}

\author{
Johann Visagie \\ Department of Philosophy \\ University of the Orange Free State \\ BLOEMFONTEIN
}

\begin{abstract}
A theory of macromotives

This essay sketches in outline a theory of macromotives. The latter term refers to certain encompassing themes, something like ultimate values, which are of directive importance 10 cultural development and span cultures ancient and modern. lirom a possible class of such motives, four are idenufied: the motives of nature, knowledge, power, and personhood. They are discussed in turn, with attention to their individial histories, and also w'th a view to analysing the kind of "emotive" logic by which each of these notives contends for the status of final point of reference. Then follows a bricf reflection on the ways in which these motives not only impact on world history, but also on some of the most intimate aspects of our personal lives. The pemiltimate section is devoted to a comparison of the approach developed here with Dooyeweerd's theory of ground molives. The essay closes with a brief reflection on the posimodern questioning of nelanarratives.
\end{abstract}

\section{What are macromotives?}

One can loosely define the object of our inquiry in the following way: "macromotives" are encompassing themes that have decisively shaped the development of both Westem and Eastern culture, from the historical beginnings of these cultures right up to the present time. These themes take the form of something like ultimate values that inspire and motivate (hence their being designated as "motives") not only individuals, but also pattems of collective social behaviour and even cultural concerns of an epochal nature. In the latter case one finds changes in value-profiles helping to initiate new types of thought and behaviour, in for example the era of antiquity, the Middle ages, and the modern period. Macromotivational values are profiled within such historical time-frames by being "translated" into an assortment of cultural concems that become characteristic of a particular time-frame. Examples of such concerns with regard to our own epoch are: Individual Liberty and Technological Progress. Given the significance that concerns like these have in current cultural time - and that comparable concerns have had in other time-frames - it is not so surprising 
that we find it in the very nature of macromotives to effect in us feelings of the deepest awe and admiration.

In this article four macromotives will be introduced, macromotives whose character and impact are in keeping with the general description above (though I will focus mainly on the Western cultural context). These motives will be presented as "phenomena" that have confronted humanity, throughout the course of its evolution, in the most overwhelming manner - phenomena that are transcendently magnificent in what they are and in what they do; phenomena, also, that seem to exist at the limit, or rather, to constitute the limit, of what we ourselves are and what we can hope to do. Faced with manifestations of such grandeur, individuals and civilizations have always felt the urge to turn to these manifestations as the objects of their greatest concern, their highest tributes, their noblest efforts.

\section{The motive of nature}

Probably the first phenomenon of this kind that ever filled human beings with a deep and lasting wonder was nature itself. Here was a looming presence, a brooding assembly of indestructible forces: elemental and amorphous, yet aggressively alive. These restless forces literally surrounded primitive humanity and completely controlled the life of the tribe. As we know, the people of the tribe often experienced themselves as virtually the expression or extension of these forces. The latter flowed through human beings no less than through animals. They moved in a mysterious way, their cyclic wonders to perform. Rivers, forests and mountains too, shone with a spirited aliveness. Things and people had this intimate co-existence with nature from their very beginning in time. And - so it was believed in some of the most ancient religions - it is to this unformed and unknowable nature that they always returned, in the ceaseless and cyclical flow that deternines the existence of all individual things.

Through the centuries, humanity's experience of nature has evolved from these beginnings to perceptions that are, of course, markedly different. Yet an essential continuity has been preserved. For even today we often still feel engulfed by the great pre-cultural world in which our personal lives attain the significance of dust. Although now we shudder not so much before a wilful nature that intimately and capriciously touches our existence, as before a scientifically disclosed universe that finally and silently presides over "man's search for meaning".

In comparing these two different experiences, an interesting question arises. Is the current scientific picture we have of the universe - an explosively born, swiftly expanding mass of swirling galaxies, star-sucking "black holes" etc. necessarily the "real" picture? Some scientists see no compelling reason to assume that it is. Perhaps our picture is, in fact, a likeness of just one of the faces 
of the universe. The latter face in effect being one in a long row of masks that the universe has donned, from time immemorial, in its dealings with inankind. 1 But if this is indeed the case, then it seems to be all the more reason for us to think with even greater reverence of this universe in which we live, move and have our being. Because we then realise that this universe is simply too great for us to have any adequate image of it - ever. Unlike the images of their God that were prohibited to the people of Israel, images - in the form of scientific models - of our universe are indispensable to us. But sometimes, in the end, they seem to be equally inapplicable. In relation, that is, to a Face which simply cannot be gazed upon or imagined.

What should also be taken into account here, is that not only is our overall picture of the universe continually changing - we also find in modern times the constituent features of any given picture constantly being revised: sometimes with far-reaching effects on the broader picture itself. Compare, for example, a newspaper report of some years back with the heading: "Looking at the universe with new eyes" (Sunday Star Review, 1991-01-27). In this report it is stated that scientists' theories about the formation of galaxies have quite suddenly been thrown into disarray. The cause of this is the ongoing deciphering of massive amounts of data received from a spacecraft that was launched in 1983. The significance of the data is only now becoming apparent to scientists. The report states that "up to last week" it had generally been believed that the universe was evenly filled with stars and planets. But now the new data suggests that in fact huge voids fill the universe, interspersed with the occasional massive cluster of galaxies. An astrophysicist from Oxford was quoted as saying: "Can we please have a new model for the universe as soon as possible?"

These masks of the universe that we seemingly have to content ourselves with how have they actually appeared to us in history? A specialized historical study of nature as a macromotive would have to delve into this question in detail. In the present context, I can only refer the interested reader to an excellent sampling of such a history in an acclaimed book by physicist Edward Harrison (which I have already referred to, see note 1). Among the "universes" (that is, the masks of the unknown universe) that this author distinguishes, from the beginnings of cultural history and up to (but excluding) the present scientific conception of the universe, are the following: the magic universe, the mythic universe, the geometric universe, the inedieval universe, the infinite universe, and the mechanistic universe.

I For an interpretation along these lines, sec Harrison (1985). I borrow the mask analogy from him. 
A theory of macromotives

Harrison's succession of "masks" is one way of reading the history of the universe. There are also ways of reading the history of natural reality in the narrower sense of this concept - namely as earthly or environmental nature. One could, for example, study the way that this aspect of nature is perceived in terms of (broad) cultural-historical time frames, like those of antiquity, or the Middle ages, or the age of Enlightenment. Parallel to Harrison's periodisation, or superimposed upon the latter, we could thus distinguish a succession of environmental images. With reference to the three time-frames just mentioned, one could perlaps speak of organismic nature, idealistic nature, and mechanistic nature ${ }^{2}$ An interesting modenn-day development in the history of nature is the so-called Gaia hypothesis, developed by the British scientist James Lovelock. According to this theory, the earth is to be thought of as a single, giant organism. If this model becomes broadly accepted, we will, in a way, be witnessing a significant return of the organismic perceptions of antiquity. ("Gaia" was indeed the name of the Greek goddess of the earth ) This time, however, these perceptions will be founded not on a mythic world picture, but on sophisticated scientific analysis. Of course, the development of organismic models of nature has also been advocated for some time now by environmental enthusiasts and New Age activists.

Returning to the theme of nature in the expanded sense of universe, a decisive question arises - one to which we shall return in the context of the other macromotives. Why, and by what logic, is it possible for nature in this sense to evoke a species of semi-religious feeling in the minds of people? The first type of, let us call it "emotive" logic, that is connected to this specific macromotive (in its modern world context) is, I believe, a spatial one. It is in our spatial experience of reality that we encounter part-whole relations in their original (nonanalogical, non-metaphorical) sense. And it is the logic of parts and wholes that is fundamental to the feelings of awe that the universe inspires in us. For nothing is so inclusive as the universe. The universe is even per definition that which is all-inclusive. But for the universe to be all-inclusive, for anything to be allinclusive, means for it to be ... like God. ${ }^{3}$

The second type of logic that accompanies nature - now in the narrower sense is a numerical one. It revolves around our intuitive experience of an order of

2 For some brief historical notes along these lines, sec Schuurman (1977:25-39).

3 Cf. the following sentiment: "The Universe is eventhing. What it is in its own right, independent of our changing opinions, we never know. The Universe is all-inclusive and includes us; we are a part or an aspect of the Universe experiencing and thinking about itself" (Harrison 1985 1). For a discussion of classical thcological models of God as a "containing" Being, sec Kremer (1969). 
time that is expressed in relations of priority and succession: the sequence of first, second, third, an so on. In this context, people think of nature as being the primary reality, out of which everything else emerged. Such has the impact of the philosoplyy (for it is indeed much more than simply a scientific theory) of evolutionism been on our life and world view, that this particular logic of the nature motive has become the most persuasive logic when it comes to thinking about humanity and history. And here, too, nature becomes like God, now in the sense of "being in the beginning".

\section{The motive of knowledge}

Thus, at the dawn of human existence, nature prevails. It was, however, not long before cracks and fissures began to appear in the dome of physical and vital forces that enclosed human existence from all sides. These fissures were effected by a capacity that human beings began to discover within themselves: the capacity to produce knowledge and understanding. For this capacity went hand in hand with the ability to conceptualise, to analyse, to gain insight by means of seeing into the nature of things. This ability meant that not only the nature of things, but more significantly, the things of nature itself became prone to a certain demystification, a certain desacralisation. These things of nature were liable now to be laid open before a truly inquiring sort of perception, and so to be penetrated by a gaze that was far more powerful than that produced by the organs of mere physical sight. This was the roving gaze of the human cognitive faculty - turning to, and fixing upon, nature. 4

To analyse, to comprehend, to reason: one who is capable of these feats, breaks free from the mesmerising power which brute facts and forces hold over the fragile beings which they confront. Knowledge, of course, eventually raises its sights higher than the facts and forces of nature: it begins to target the world of culture, the world where history is made, where art is created, where science is practised, where good and evil themselves make an appearance. And it is here at this latter point, at this very summit of human understanding, the pinnacle of truth where good and evil seem to yield to distinction and definition, that knowledge makes "man" to be like God (as the snake suggests in Genesis 3). It is noteworthy that the Bible story depicts knowledge as the very first idol that human beings - still completely surrounded by primitive nature without being intimidated by it - lusted for.

4 The beginning of this struggle of knowledge against nature is magnificently thematised in Horkheimer and Adorno (1973) They see this beginning as being brought to its full potential (disastrously so) in the cightecenth century, the age of Reason. 
From its inception knowledge has had a glorious history. One of the earliest highlights was the Greek pursuit of theoria: the contemplation of the inner, true nature of things. It was presumed to be in the power of this earliest form of "theory" to disclose real - as opposed to apparent - reality, that is, to reveal the immutable and etemal being that hides behind the pulsating hustle and bustle of daily life. In the course of time, this theorised type of truth developed into what eventually becaine scientific knowledge as we know it: a way - the only way that modem people are aware of - that leads to sound and efficient and trustworthy relations with ourselves and the world around us; a way that extends even beyond these destinations, taking us from our libraries and laboratories to the farthest reaches of the universe.

There is something else about knowledge: a remarkable endurance. While everything fades away with the passage of time, the symbols of knowledge remain. And, in general, they will always remain. Even if much of what humanity has erected upon the face of the earth is one day destroyed, there will, in all probability, be something that remains. If beings from other worlds, other universes, should at one time in the future come across our devastated planet, they will find the remnants of thought - artefacts (books, tapes, instruments etc.) that will bring them face to face with objectified knowledge. And it is this face of knowledge that is enshrined with a particular grandeur. That which any one person knows scientifically at any given time is already tremendous in power but this conscious and subjective knowledge is no match for the staying power of transconscious and objective knowledge. This anonymous knowledge speaks to us and watches over us in the myriad creations of science, art and technology, and of culture in general. 5

In our discussion of the nature motive above, the question was asked: by what peculiar "emotive" logic does this motive evoke feelings of awe and submission in us? The suggested answer drew our attention to the enclosing capability of nature (the latter understood in its expanded function of universe). But what of knowledge? Is there a similar feature, a unique characteristic, by which knowledge convinces us of its own majesty and power? There are, quite possibly, a number of such features. But let us look at only one - perhaps the most important one, at least for people whose relations with knowledge are of an essentially modern type, that is, dating from about the eighteenth century. For it is approximately since then, that we have become increasingly aware, or have

5 A comprehensive theory, one could even say a kind of theo-ontology of objective knowledge is devcloped in the writings of the famous philosopher of science, Karl Popper. Sec Popper (1975) for diverse cssays relevant to this theme 
been made effectively aware by scientists and philosophers, of the constituting capability of knowledge. 6

One way of describing this particular capability is to say that knowledge represents things. In the knowledge that we have of objects, they always appear to us in a specific form. They are not simply what they are; they are what our knowledge makes of them, or more correctly, what our knowledge makes them out to be. Knowledge, in fact, frames things, structures them in certain ways, portrays them by forming pictures in our minds. In a certain sense, things seem to exist only in the conceptual pictures we have of them. The mind's eye does not passively register things and facts and actions - it brings systems and patterns and complex organizing principles into play.

I should at this stage point out that, although the model of the constituting mind has a "surface" history leading back to the philosophers of classical rationalism (Descartes, Leibniz, Kant), it has a "deep" history reaching back much further. What is essentially at stake in proclaiming the constitutive power of the mind, is thus a decision to grant inner reality priority over all outer reality. And we find this decision, as such, already being made by prominent thinkers of the Hellenistic age. ${ }^{7}$ What happened in modern times was that the mind's priority over outer reality was given an increasingly stringent scientific foundation.

In any case, if it is true what contemporary philosophers, psychologists, biologists say of the mind's representational structure, can we then think of anything more primary than knowledge? 8 Everything - that is, everything that exists in our world of experience - is in some way made the way that it is, by knowledge. From this perspective, we can thus see knowledge bringing order even to nature itself. Accordingly, it might seem quite appropriate to award victory to knowledge over and against nature, in this, a possible first round in the eternal conflict of the macromotives. ${ }^{9}$ But then there are some other motives, which have not yet had their say in this presentation.

6 The philosophy of Immanuel Kant (1724-1804) played an important part in convincing pcople of this particular capability of knowledge Sec Kant (1965)

7 An insightful history of the "inncr/outer" theme, among five other themes foundational to Western thought, is found in Hcimsocth (1922).

8 For a very comprehensive overview of recent interdisciplinary approaches to the representational structure of the mind, see Gardner (1987)

9 The relation between nature's apparent causing of knowledge (such as we would find, for cxample, in theorics of the cvolutionary development of knowledge in the human species), and knowledge's sceming creation of nature (by way of the concepts constituting our expcrience of the latter) can be a scrious problem for modern-day philosophers. For 


\section{The motive of power}

The concepts of knowledge and power are traditionally closely associated. We all know the saying that knowledge is power. But, although knowledge certainly does represent power of some sort, this power is but a pale reflection of "pure" power, of power in itself. What is power in itself?10 More important in the present context, what is power as a macromotive? And how does it relate to the two motives already discussed? In biblical inagery, we must now depart from the garden of Eden (nature and knowledge) to visit the tower of Babel (power).

The first thing to notice is that power does indeed "play in the same league" as the motives of knowledge and nature. It possesses the same kind of presence, the same radiant significance in relation to everything personal, social and cultural. It appears to us throughout history as something that creates, binds, drives, channels and changes. And it does this both to things and to people. Power, in brief, reigns: power is reign or rule itself. Something that is important in this depiction is the element of purposeful action. Power is a very special kind of force: it is only actualised in relation to, or in the context of, the various goals that human beings set for themselves - their plans and projections, their ambitions and desires. In this respect, power is definitely not a blind force (devoid of any rational element) like the forces of nature. Power always makes its entrance into the world whenever people start to imagine, in a quite logical way, changes to the face of the world around them - however small or great the scope of these changes might be.

And with this last thought we have arrived at a position where we can see something of the relation between power on the one hand, and nature and knowledge on the other hand. Of course, the way in which we interpret this relation, is wholly determined by our answer to the question: Which of these two macromotives do you respect most? In the present section we are allowing the motive of power to speak with full authority to us. And in the grip of this

remarks on how this problem presents itself in the thought of the well-known social theorist Jurgen Habcrmas, sec McCarthy (1978:111)

10 Strictly speaking, power or any other phenomenon that we may encounter, does not at any lcvel exist "in itsclf". Everything is intrinsically related to many other things, and all things bear in themselves traces of the variously structured relationships within which they exist Such relationships are in fact constitutive to the individual identity of things. The (non-) theory of deconstruction. authored by French philosopher Jacques Derrida, and popular with the exponents of so-called postmodern thought, can be credited with providing a novel (if completely onc-sided) insıght into this state of affairs The idea of a thing cxisting "in and for itsclf" is basically a heritage of Greck metaphysics, and is in conflict with just about every modern philosophical and scicntific assumption about the nctuork-likc interconnectedincss of reality. 
authority it will appear obvious that power is even greater than both nature and knowledge.

First, as regards nature, it has already appeared that the latter can never appropriate the distinctively rational element inherent in the operations of power. Nature is vast, but there is no method to its vastness. Further, power in this way not only seems to rise a step above nature; it also manages to change nature. Think only of what technology can do to nature and remember that the former is but a name for power.

Second, as regards knowledge, here too power must seemingly triumph, for, however great an achievement the acquiring of scientific knowledge of nature is, is not the exercising of technological control over nature, a still greater achievement? 11 And does this trump that power holds over knowledge not also apply in the case of their relation to society (whether the power here is technological or political in nature)? 12 Moreover: is knowledge itself not subject to the machinations of power? It really does seem that if history has taught us one thing, it is that knowledge does not lead a liberated existence. On the contrary, we find that it is time and again controlled, directed, usurped, used in the interests of (some or other) power. And it is apparently only through enlisting the help of a saviour-power and humbling itself before this power, that knowledge can try to free itself from rejected forms of power.

The history of power in Western culture is marked by a significant turning point that occurs in the context of Christian theology and philosophy. This point is reached when the preoccupation with divine knowledge is superseded by the preoccupation with divine power. Now the realisation dawns that, though it is a glorious thing to wholly comprehend the good, there is a still more glorious thing, namely the absolute competence to decide the content of the good, to lay down its law.

From the time of the Greek philosophers, the pure intellectual faculties of hunan and divine agents enjoyed a certain primacy. To a remarkable extent, this

11 Adorno and Horkhcimer, in their critique of Western rationality, do not always take into account this clear distinction between knowledge and power. Of course, any analysis should be free to treat knowledge and power as a kind of complex (which is also what Foucault sometimes docs) It cven secms natural to assume that macromotives do indeed enter into combined operations of various sorts. Nevertheless, it secms to me that one should start from a clear understanding of the primordially competitive relation between macromotives (in terms of the interpretation accorded them).

12 One is reminded here of Karl Marx's famous statement that, while philosophers have for so long sought to interpret the world differently, we should now come to actually try and change the world 
changed during the course of, roughly, the thirteenth and the fourteenth century. During this time a new style of philosophical and theological thought emerged, known as nominalism. ${ }^{13}$ This novel trend (which is still a dominant influence in epistemological theories of the present time) developed new models of God, humanity, the world, and the interrelationship between them. In these models, Greek intellectualism mostly came to be replaced or at least relativised by earlymoden voluntarism: the doctrine of the primacy of the will. In terms of theological thought, the shift that we touched on above was introduced: God's will, and thereby his power, became the very essence of the divine nature. This had subtle but significant consequences for perceptions, attitudes and mentalities far removed from the field of theology 14 Will, power, sovereignty, rule and order became newly appreciated attributes in a variety of contexts. (Or perhaps it is possible to say that there occurred at this time a shift to voluntarism at a certain level of general cultural experience, which only came to be expressed in, among other things, doctrinal theology.)

This late medieval flowering of voluntarism was actually foreshadowed, many centuries before, in the early beginnings of Christian theological reflection. During this period, the Christian picture of God had much in common with the way that the office of the Roman emperor was viewed by the inhabitants of this great empire. It was precisely the inperial qualities of divine rule that were stressed in what is sometimes known as "Latin" theology - which takes us back to another great moment in the history of power: the very existence of the Roman empire itself. This empire was based on an obsession with power such as the world had never seen before; an obsession which was not only a matter of certain social and cultural features (for instance the enormous judicial authority wielded by the husband and father - the pater familias - within a household) or of an idiosyncratic emperor cult. It was also akin to something like a collective ethos. Thus not only the "body", but also the "soul" of Roman society, bore the imprint of a pervasive power idealism.

Early medieval society was structured in ways that represented another step forward in the march of power. In the period of Constantine, the church developed into a cultural colossus that was also a very refined instrument of social control. On the one hand, the church was in a position to preside over and sanction the "earthly" power of the state; on the other hand the church just could

13 Nominalism teaches that universals only exist in the nind as concepts, and not in reality as structures or essences.

14 For insightful historical analyses of nominalism and voluntarism in theology, see Oberman (1967) and Knowles (1962) Klaaren (1977) traces the effects of these styles of thought on the emergenec of modern science 
not resist initating the prancing power posture of the state. The power posturing of the church was developed along two strategic lines: internal administration and external conquest.

Finally, in this very selective overview of highlights in the history of power, we come to contemporary culture. How does the present deployment of power compare to its politico-ecclesiastical structuring in pre-modem times? Well, this very same structuring actually called forth, in formidable opposition to itself, a power formation that really inaugurated the modern era: the pervasive discourse of emancipation from domination. This discourse has mobilised - through the course of centuries - plilosophies, movements, revolutions, paradigms and practices that have shaped the modern world. But, just as was the case with the medieval deployment of power, there is more than one line of development to be considered here. In fact, the complexity of modem power relations is very much greater than it could ever have been during any other period of history. We find, in the first place, that the power manifested in our culture by the discourse of freedom and emancipation, is decisively countered by an impressive array of institutional powers. Science, technology, administrative bureaucracy, economical imperatives, the modern mass media - these are all concentration points of power on the higher systemic levels of Western culture. Individually and collectively they pose a threat to the individual's enjoyment of total freedom in body and mind. Except for these "ligher" manifestations, much more mobile power formations are also active at the middle and micro levels of our culture. Consider for example the functions of what I will call "protective power". Health and medical care, state-sponsored security, the so-called "therapeutic industry", educational systems, and so on - these are the power structures that today facilitate our access to the last word in organised intimacy, care, guidance and protection. It is specifically at this level that a differentiated network of power outlets has come to totally supplant (but in effect also imitate) the monitoring functions of the monolithic church-state machine referred to above. The functions of this church-state machine were similarly directed to taking institutional care of the individual - although of course the soul was considered by the church to be more important in this regard than "feelings" and "self-expression" and "survival". 15

Having sampled some of the great moments in the history of power, let us now take passing note of what might be terned the psychological profile of power. Many psychologists, sociologists, philosophers and theologians have postulated a

15 The relations of carc and protcction described here touch on what Foucault has in mind with his notion of "pastoral power" (sce Dreyfus \& Rabinow, 1982:214ff). However, on account of his extreme nominalism, he would never agrec to interpreting such relations from the standpoint of a macromotivational theory of power 
deep impulse in human nature, underlying most of what people do with their lives. This impulse can be called the will to power and glory, ${ }^{16}$ a will which, it must be granted, is not always that obvious in the behaviour of people. As some psychological studies tried to show, it is certainly not only overtly ambitious and aggressive attitudes in people that reflect this will. Patterns of behaviour that seem to be the very opposite of such attitudes (for example the willingness to have people walk all over one; or the urge to escape from the world of competition and achievement) may in fact also give expression to the universal desire for attaining some kind of supremacy or superiority (cf. Homey, 1945; 1950). In individual as in cultural history, so it may seem, relations of power ultimately determine the course of events

To conclude this section, let us now pose the same question as we did above, in connection with the other macromotives. By what emotive logic does power actually take hold of our imagination and lay claim to our lasting admiration and allegiance? Nature and knowledge, we have seen, inspire and intimidate us by their respective abilities to include and to precede, to represent and to constitute everything that exists. Power, however, makes its own unique impact on our minds. It does this, I would suggest, by intimating to us that all the things we see rising above mere nature, from great cultural achievements to the most mundane actions that can in any way bring about something new and creative; that all these things are in the end nothing but varied manifestations of the capacity to purposively effect change. This capacity would seem to be the real origin of everything that bears the mark of design and desire

\section{The motive of personhood}

The fourth and last macromotive to be introduced here, is that of personhood. This is the motive that places the human self before us. In the grip of this motive, we are confronted with the phenomenon of the person as a majestic and mysterious presence, a living presence that can address us and the world around us like no other being or force on earth can. Central in the theme of this motive is the element of subjectivity: a subjectivity that is entrancingly active and alive, the source of an unending stream of thoughts and acts that range freely and creatively over all sectors of reality.

16 A typical theological perspective vicws sin as involvung essentially man's striving after divine power and glory. Psychologists who have made illuminating studies of the craving for power arc, among others, Alfred Adler and Karcn Honcy: And it was of course Nietzsche who, in modern times, gave classic philosophical status to the idea of a pervasive will to power. Foremost in their acknowledgement of this status at the present time arc a number of philosophers of the post-structuralist persuasion 
In a sense this macromotive comes nearer than all the others in attaining a presence similar to that of God - that is to say, similar to what human beings have always imagined God to be like: an acting and experiencing Subject of infinite magnitude. And even where we find the idea of the divine expounded in impersonal concepts, like that of being or totality or nature, these concepts are often attended by metaphors that tend to personalise, to some extent, the matter at issue. We may even speculate that the underlying reason for this sort of personification is to be found in the fact that the attributes of personhood are tailor-made to indicate that which transcends our capabilities for objectification and manipulation. $\mathbf{1 7}$

Consider for a moment how personhood might fare in the contest of the macromotives. Regarding the motive of nature, personhood might seem swallowed up by the vastness of nature which surrounds it. And of course, nature not only surrounds human individuality; it forms a basic part of this individuality in so far as the human body and its brain can be seen as a manifestation of nature. But when one heeds the voice of personhood, one sees this perceiving body as being capable of a super-natural feat, as it were: being acutely conscious of itself. Vastness is great, but is surpassed by the consciousness of vastness.

In relation to knowledge, personhood may seem to be enveloped by the great systems of objective and anonymous knowledge that have been developed in the history of science. In the context of these systems, personhood is perceived to be primarily a field or an object or an element of knowledge. But from the vantage point of the forner motive, the great body of objective knowledge contained in books, papers, theories, arguments etc. cannot be considered to outrank its origin and destination - the subjective user and producer of such knowledge.

As to power, again personhood may seem to shrink into insignificance beside the resources and the sheer cultural reach of this macromotive. Yet one simple question brings quite another perspective: can power give an account of itself - or judge itself? On the contrary; it is up to people, to persons, to personhood - to sit in judgement of all forms of power. And even if this judgement is delivered from a position of captivity to power, its moral reach is indubitably beyond the highest level at which pure power can ply its trade.

17 The German theologian, Wolfhart Pannenberg, has put forward some interesting ideas in this connection, exploring new perspectives on the relation between the personhood which is attributed to God, and that which is experienced on an inter-personal level For some discussion, scc Brinkman (1980:45) 
A theory of macromotives

\section{- Personhood experienced as being separate from the natural environment}

As with the other macromotives, let us look briefly at some significant stages in the historical development of personhood. The history of personhood really begins at that hypothetical point where human beings come to experience, for the first time, their real separateness from the natural environment. At this time, there presumably arose a gradual understanding of the differences between the way of personhood and the way of nature. This is of course the beginning, also, of the inroads that culture would make into nature.

In fact, at this point we see a macromotivational "alliance" of power and personhood arraigned against the forces of nature: the one member of the alliance bent on victory over nature by directly controlling it, the other in a position to subject nature by reflectively experiencing it. Persuaded by the macrologic of personhood, one can of course reason that the latter conquest is of foundational importance for the former. To put it in other words: power only exists there where personal individuality has come into its own. The same relation holds, one could argue, between knowledge (science) and human individuality.

\section{- The quest for personal transformation}

Another notable development in the history of personlıood occurs with the beginnings of the quest for personal transformation: the individual aspiring to consciously mould his or her manner of living, so as to become more happy, more wise or more holy. In the history of Western culture, this aspect of personhood starts coming into its own with the earliest beginnings of Greek philosophy, the legendary Pythagoras (6th century $\mathrm{BC}$ ) being a major figure in this regard. But it is specifically the Hellenistic and Roman periods that saw this aspect of personhood attain, for the first time, a real and encompassing cultural significance. During this time the study of philosophy itself was largely associated with ethics, while the latter was mainly associated with transformational practices of some sort; that is, practices that will aid the changing of the self into a desired state, and also help to maintain or enhance the latter.

It should be noted that the transformational aspect of personhood was by no means confined to Western culture. Eastern religions and philosophies were and still are - heavily imbued with the very same ideal. Hindu systems, Buddhist philosophy, Chinese Taoism: they are all fundamentally involved with the art of disciplining the self. In the East, the broad cultural and social effects of this art were even realised much earlier than in the West.

\section{- Personhood as a regard for the form of human nature}

Let us turn now to another major development in the history of personhood; a development which also concerns another aspect of this macromotive; one that is significantly different from the transformational aspect just discussed. This 
aspect has to do with personhood as an ideal inspiring not so much a repertoire of transformational practices, as a certain regard for the form of human nature. At the beginning of the modern era, this regard came to be expressed in the language of humanism, and there sounded a new discourse on the subject of sovereign "man". Though the praises of the human race have been sung since the time of antiquity, the kind of humanism that decisively shaped modern Western thought, only began to take shape from about the fifteenth century.

A classic example of this essentially modern type of humanism is the rhapsodic text by Pico della Mirandola (1463-1494) entitled De Hominis Dignitate (The Dignity of Man). Here is an excerpt from this work (quoted in Bainton, 1962:177) in which God addresses "man" (through Adam) in the following way:

\begin{abstract}
We have conferred upon you, o Adam, no certain seat, no proper form, no peculiar function, that you might opt what seat, what form, what functions you prefer, to have and to hold by your will and your choice. Others have their nature prescribed by Our laws, but you may set your own bonds with no constriction, in accord with your arbitriment in whose hand I have placed you. I have set you in the middle of the world that you may the better survey what is in the world. We have made you neither celestial nor terrestrial, neither mortal nor immortal, in order that as a free and sovereign modeler and sculptor, as it were, you may fashion yourself into the form which you prefer. You are able to degenerate into the lower forms, which are the brutes, and to regenerate yourself by your own volition into the higher, which are divine.
\end{abstract}

Note that, although mention is made here of man's ability to fashion himself into the form of his preference, it is in fact not the transformational aspect of personhood that is motivating this particular discourse. Rather it is another aspect of personhood, one which looks in awe on the place which the human spirit occupies in the natural world. In other words, it is not the endeavours of the individual to give a certain aesthetic form to his personal existence that is spotlighted here; it is the potential of the human species, as such, to realise the most exalted forms of freedom and creativity. And this realisation is mostly brought about by way of the great cognitive and cultural achievements for which humanity (the collective manifestation of personhood) is destined.

\title{
- Personhood as a resistance to optimistic humanism
}

To close this sampling of the history of personhood, let us look at one more highly significant development. It was during the course of the nineteenth century that a remarkable resistance to the optimistic humanism that we have just outlined, began to take shape. Some thinkers - such as Kierkegaard and Nietzsche for example - began to call attention to another aspect of personhood. Not the species-specific faculties whereby humans rise above nature and 


\section{A theory of macromotives}

necessity is the theme here; rather it is the stark realities of concretely experienced life, exposing all idealistic approaches as empty and futile. This latter aspect of personhood was taken up and developed by various modern movernents and trends, in recent times most notably by the existentialist, poststructuralist and neo-pragmatist philosophers (Heidegger, Sartre, Lyotard, Rorty and others).

The language that personhood speaks in these latter philosophers still abounds with concepts like morality, freedom, creativity - just as was the case with the classical discourses of this macromotive. But now, in existentialism for example, these and other concepts refer to the inner acts of the lonely individual struggling valiantly, if vainly, against alienation, despair and death. The ethics of this struggle relates in the first place not to the technologies of transformational lifestyles, but to the authenticity of lived experience. It is interesting to note that even though the experiential element is quite prominent in this particular manifestation of personhood, it is nevertheless a certain theoretical insight into the nature of human experience that is ultimately essential here - in contrast to the repertoire of practical techniques and styles and exercises that is so characteristic of the transformational ideal. 18

Finally, as the last of the macromotives being reviewed here, personhood also needs to be considered from the vantage point of its own emotive logic: that unique operational feature which, more than any other factor, enables a macromotive to establish its apparent power and superiority.

Recall again our findings on the emotive logics of the other motives we have looked at. In the case of nature, it was especially the power of being able to enclose; in the case of knowledge, the power of being able to constitute or represent, in the case of power itself, the ability to effect change. What would be the distinctive feature that is capable of elevating personhood above the accomplishments of all these other motives?

In our introductory remarks on the general make-up of this motive, we seem to have already touched on this one essential feature. It is nothing else than the

18 Which is of coursc not to say that the "cxperience" associated with this ideal is of a kind which cannot also be explored or expressed theoretically. The point is only that transformationalism in modern Western societies is not so much a defined philosophical view of life (like existentialısm), as a search for a noble way of life. Again, this does not mean that there can be no conceivable connection between existentialist ethics and modern transformationalism Historical evidence, which I will not review here, is to the contrary. 
power associated with full subjectivity: the power to experience things, and the power to give direct and unmediated expression to this experience.

\section{The number of macromotives and how they touch our personal life}

Having looked at a few macromotives, their inner emotive logic and some highlights in their historical development, let us return again, by way of a summary perspective, to the general form and function of macromotives, and then reflect on the manner in which the latter surreptitiously penetrate our existential experience of the world.

At the beginning of this article, these motives were introduced as a set of encompassing themes that have decisively shaped cultural concerns throughout the ages. They are themes that motivate, on the level of ultimate convictions, individual thought and practice, as well as collective social behaviour. Spanning great historical divides (such as the passing of antiquity into the medieval period), they do, however, take on forms and functions that are characteristic of the cultural epoch in which they operate. The motive of knowledge, for example, operates in modern culture largely by way of the expression it receives in science and technology. Macromotives are further characterised by the feelings of awe and reverence which they evoke in people: each motive being able to present itself as the ultimate phenomenon, the deepest mystery or the highest value, that humans can ever be confronted with.

A question that arises in this context is: Just how many of these macromotives are there? Although the four that have been introduced above, have always struck me as being prime examples of what one wishes to capture with this concept, it seems a bit improbable to believe that there are actually only four of these motives. There may indeed be others. Probably much has already been written about them, in other contexts and using different viewpoints than the present one. In terms of the framework articulated here, the important thing to keep in mind when reviewing other potential motives, is that whatever "candidate" presents itself to our analysis, it should be expressive of the same kind of ultra-reality which these other motives can lay claim to, to be acceptable to this rather exclusive club.

\section{- The concrete relevance of macromotives}

Let me conclude this section by reflecting for a moment on the concrete relevance that macromotives have for our daily lives.

Consider, by way of example, four phenomena that touch all of us intimately and overpoweringly: information, authority, love and death. 
Information is what we seemingly need to survive in the "Third Wave" world we (are coming to) live in (cf. Toffler, 1980; 1990). This is claimed to be a pervasive need that none of us can really escape. But surely it is also a haven that many of us turn to, to find diversion, insight, meaning. Being aware of our past, realising what is presently happening to our community, our society, our world, our cosmos, is what counts. It is as if in some way we are miraculously delivered even if only for a moment - from the circumstantial prisons in which we find ourselves, if we can only acquire some factual knowledge of what is really at stake, what is truly worthy of our attention and understanding.

Authority is something known to everyone of us. We wield it, or we meet with it: according to different situations we find ourselves in. Either way, it very much determines the shape of things in and around our lives. And coupled to values like position and prestige, the figure of authority comes to loom large in the dreams of many who are not satisfied with mere survival or even with the pleasures of the good life

Love, mostly in its romantic form, is regularly praised as the most wonderful experience anyone can have. The gaze of the beloved appears to be able to bring meaning into the most despairing life. And one can immediately feel the argumentative force of Meursault's judgement (in the novel The Stranger by Albert Camus) that none of the certainties dear to a priest are "worth one strand of a woman's hair".

Death intrudes into our lives as the ultimate and untimely horizon. The last word always belongs to the grim reaper - the implacable representative of the great Order of Things; the order which not only swallows up plans, people, and power structures, but also civilizations and cultures and, perhaps, one day, history itself.

No need to demonstrate in detail that, what has been at issue in the above remarks, is the surrender of human beings, in their innermost lives, to norms and values and facts that finally fall under the shadow of macromotivational realities. Knowledge (in information), power (in authority), personhood (in love), nature (in death) - they not only speak decisively in cultural history, their presence is felt, sometimes chillingly, in our most intimate environments and experiences.

\section{Dooyeweerd's theory of ground motives}

The term "motive", that is used in this article to designate a particular type of idealisation constituting the object of our investigation, is borrowed from the Dutch philosopher Herman Dooyeweerd (1894-1977; author of a body of work 
dedicated to a Reformational-Clristian philosophy). ${ }^{19}$ In fact, his theory of "ground motives", as he called them, is not without influence on the way that these idealisations are interpreted in the present analysis. Also, I share Dooyeweerd's conviction that the ultimate motives that predominate in culture and society are in fact idolisations, and should therefore be the object of a critical theory. (Though, in contrast to Dooyweerd's rather optimistic view on this point, I do not believe that any critical reflection can escape being somehow, at some point, somewhere along the line, seduced by these awesome phenomena that enter into common human experience.) I further agree that a critique of idolisation can best take its starting point in (what I would term) the JudeoChristian "feel" for a fundamental divide that exists between a life-giving Word and the world that it addresses.

But there are important differences between the present analysis and the approach taken by Dooyeweerd. For example, his theory distinguishes three "dialectical" (that is, in practical terns: open to critique) ground motives that successively constitute the deepest spiritual impulses of three great epochs in the history of Western civilisation, namely the Greek motive of form and matter, the scholastic motive - active in the Middle ages - of nature and grace, and the modern humanistic motive of nature and freedom. The two poles of the humanistic motive are sometimes also referred to as, respectively, the ideal of science and the ideal of personality. (A fourth and non-dialectical motive, that of the Christian religion's commitment to a divine revelation concerning creation, fall and redemption, was early on compromised in Byzantine culture and then in the scholastic synthesis, coming briefly to the fore again with the Reformation. But this motive is considered by Dooyeweerd never to have had - in its pure forn the same pervasive cultural impact that these other motives had.)

The macromotives discussed in this article differ from the spiritual forces posited by Dooyeweerd, in that they have been shown to cut across all epochal or historical or cultural divides. This means that personhood, for example, as it has been interpreted in this article, cannot be the same as Dooyeweerd's ideal of personality (the latter constituting one pole of the humanistic groundmotive). The former is based on an emotive logic that evidently transcends the cultural "mindset" of the humanistic paradigm that Dooyeweerd is concerned with.

On the other hand, I do believe that Dooyeweerd is correct in attaching great importance to the matter of cultural contextualisation. Indeed, it is inevitable that a macromotive such as personhood will today be experienced in an epochal

19 Dooyewecrd's magnum opus is his 4-volume work entitled $A$ New Critique of Theoretical Thought. which first appeared in the Dutch version in 1935-1936. See Dooyewoerd (1969) 
context that is decisively different from, say, the late Middle ages or Greek civilization. And one may assume that this will be the case with all macromotivational themes. Knowledge, for example, in its impact on the moden world, can scarcely bypass the cultural steering powers of science and technology. 20 These powers act as a medium, as it were, through which knowledge, in one of its modern-day transformations, is transmitted across the whole of the cultural landscape. In antiquity, for example, the nearest equivalent to such a mediating complex, acting in the interests of knowledge, would probably be the ideal of philosophical truth. Connected to this ideal were certain guiding concepts expressive of the concerns of knowledge, such as logos and theoria. 21

\section{- The role of nature in Dooyeweerd's model}

In spite of Dooyeweerd's insistence on setting cultural-historical limits to the operation of ground inotives, however, there are in Dooyeweerd's conception certain clues that do, in fact, point to the existence of (what we have come to discen as) macromotives. Consider, for example, the role that nature plays in his model. It seems to surface, in one way or another, in each of the three culturally formative motives. In the Greek motive, the reference to "matter" has basically to do with the pervasive influence that the ancient cults of nature worship had on the intellectual and the practical life of the community. In the scholastic motive (which accommodates Greek views to the authentic Christian motive), we find "nature" designating the inherent natural order of things: an order which was, so the Church taught, supplemented by the realın of grace, faith and salvation bringing the natural world to its higher, spiritual destination. And in the humanistic motive we find "nature" posited as that which must be scientifically overcome for humanity to realise its true freedom. Clearly, then, Dooyeweerd's model comes close to recognising - if only implicitly - the universal significance of nature (in different connotations of the term) as a macromotivational force.

\section{- The way in which power is conceptualised}

We find a comparable state of affairs, when taking account of the way that power is conceptualised in this model. At first glance, the only real reference to power seems to be in the context of the humanistic ideal of science. It appears that for Dooyeweerd the latter ideal is synonymous with a certain "impulse" to dominate

20 By this I do not mean to say that science and technology arc the only steering powers. Economical, political and organizational imperatives must also be considered in this context.

21 A useful overview of some knowledge types that can be distinguished in Greck philosophy is found in Habcrmas (1973) 
nature. He even speaks of a "domination-motive" in this regard (Dooyeweerd, 1968:49). But when it becomes apparent that the so-called "form-motive" of Greek culture is analysed by Dooyeweerd as a deeply spiritual preoccupation with the aspect of mastery and control, and that the foundational dynamics of Roman culture is similarly associated with a deification of power; then again we seem to be confronted by a pervasive presence of power at the birth of great cultural formations (Dooyeweerd, 1968:40, 91; 1963:22-27).

\section{- Dooyeweerd's fixed number of ground motives and the bipolar structure ascribed to them}

Two obvious differences between Dooyeweerd's model and the present analysis, that I will simply note in passing, are the fixed number of his ground motives, and the identical bipolar structure that he ascribes to each of them. The latter structure is supposed to explain the internal "dialectic" one encounters in these motives, a dialectic that is absent - so Dooyeweerd claims - from the Christian motive. Regarding the bipolar structure of the so-called humanistic motive, it is true that Dooyeweerd distinguishes a variety of paradigms within which this motive comes to actual historical expression At the root of these paradigmatic variations he discems, however, two fundamental and opposing interpretations of the humanistic motive. They are represented by the philosophical traditions of, on the one hand, rationalism and on the other hand, irrationalism. As far as the personality ideal in the Dooyeweerdian model is concerned, these two conflicting interpretations roughly correspond to my notion of the divergence in the (modern) interpretation of personhood: either in terms of universal luman nature or in terms of individual subjectivity. The Iransformationalist interpretation of personhood (the idealisation of personal change), however, is something that does not figure as a separate systematic category in Dooyeweerd's conception of the humanistic motive.

To conclude this brief overview of Dooyeweerd's theory of ground motives, I should mention the fact that he was unwilling to have these motives considered as mere themes of philosophical reflection or as cultural-historical frameworks. The spiritual reality that he attributed to these motives entailed, to his way of thinking, the necessary consequence that they must rather be thought of as inspiring philosophical thematisation and historical periodisation. My own view regarding the kind of reality that is to be ascribed to macromotives, is, firstly, that they definitely effect the kind of overpowering awe that Dooyeweerd associates with ground motives. But, secondly, I see no compelling reason to think of macromotives as more than a select set of phenomena that evoke a certain kind of response from liunan beings. 


\section{The postmodern critique of metanarratives}

Finally, there is still another matter that needs to be addressed by a contemporary theory of macromotives. This is the whole issue of the postmodem critique of socalled metanarratives. Is a theory of macromotives not just one more attempt to construct a grand discourse on discourses, a towering edifice for the contemplative gaze, from where we may get a fix on first foundations and last horizons?

My answer to this kind of query is as follows. Firstly, it should be noted that the macromotives discussed here are viewed critically, precisely in terms of the metastatus they carry in ancient and modern discourses. Secondly, I have attempted to show how these motives can be analysed as being in the process of undermining (in a sense "deconstructing") one another, even when they seem to form combinations, wholes and unities.

On the other hand it is true that my own analysis represents an effort to subsume many different languages of thought, in terms of certain properties they have, under a comprehensive viewpoint. And this hangs together with my own belief that there is a cognitive capacity within the human mind/brain that is specialised toward the categorial conceptualisation - at a certain level of reflection - of some kind of principle or function or process, as being in some way in control of (aspects of) our experiential world. 22

Such a concept of governance is the hallmark of any discourse that intends to say something philosophically significant. The concept in question can derive its content from a host of available possibilites: anything from a metaphysical worldorder, to networks of power in society, to the idea of textuality or of contingency. In this sense, then, I would say that the dream of a deeply-impacting critical discourse in which nothing is allowed to acquire any normative meta-status, is just that: a futile dream.

\section{References}

BAINTON, R. 1962. The medieval church. Princeton: Van Nostrand.

BRINKMAN, ME. 1980. Het Gods- en mensbegrip in de theologie van Wolfhart Pannenberg Kampen : Kok. (Diss.)

CHOMSKY, N. 1988. Language and problems of knowledge. Cambridge (Mass.) : MIT Press

DOOYEWEERD, H. 1968. In the twilight of Western thought. New Jersey : Graig Press.

22 Compare Chomsky's (1988:156-158) vicw that the mind's capacity for theory construction is part of the human biological endowment This is an idea that deserves to be studied seriously, in spite of the fact that the Chomskyan turn is macromotivated by the nature/knowledge complex 
Johamn Visagie

DOOYEWEERD, H. 1969. A new critique of theoretical thought. 4 vols. Philadelphia: The Presbyterian and Reformed Publishing Company.

DREYFUS, H. \& RABINOW, P. 1982. Michel Foucault: Beyond structuralism and hermeneutics. Sussex : The Harvester Press.

GARDNER, H. 1987. The mind's new science. New York : Basic Books.

HABERMAS, J. 1973. Theory and practice. Boston : Beacon Press.

HARRISON, E. 1985. Masks of the universe. New York : Macmillan

HEIMSOETH, H 1922. Die sechs grossen Themen der abendländischen Metaphysik. Stuttgart : Kohlhammer.

HORKHEIMER, M. \& ADORNO, T. 1973. Dialectic of Enlightenment. London : Allen Lane.

HORNEY, K 1945 Our inner conflicts: A constructive theory of neurosis. New York Norton.

HORNEY, K 1950. Neurosis and human growth: The struggle toward self-realization New York : Norton

KANT, I. 1965 Critique of pure reason. New York : St. Martin's Press.

KLAAREN, E. 1977. Religious origins of modern science Grand Rapids : Eerdmans.

KNOWLES, D. 1962. The evolution of medieval thought. London : Longmans

KREMER, K. 1969. Gott und Welt in der klassischen Metaphysik. Stuttgart : Kohlhammer

McCARTHY, T. 1978 The critical theory of Jürgen Habermas London : Hutchinson.

OBERMAN, H. 1967 The harvest of medieval theology. Grand Rapids : Eerdmans.

POPPER, K. 1975 Objective knowledge: An evolutionary approach. Oxford : Clarendon Press.

SCHUURMAN, E. 1977. Reflections on the technological society. Toronto : Wedge Foundation.

TOFFLER, A. 1980. The third wave New York : Bantam Books.

TOFFLER, A. 1990 Powershift New York : Bantam Books 